\title{
Hacer la revolución. Guerrillas latinoamericanas, de los años sesenta a la caída del muro
}

\author{
Nicolás Dip (iD https://orcid.org/0000-0001-6565-7319 \\ Instituto de Investigaciones Sociales \\ Universidad Nacional Autónoma de México \\ nicolasdip@sociales.unam.mx
}

Aldo Marchesi, Hacer la revolución. Guerrillas latinoamericanas, de los años sesenta a la caída del muro, Argentina, Siglo XXI Editores, 2019.

El libro del investigador uruguayo Aldo Marchesi no hace más que confirmar la consolidación del campo de estudio sobre la historia reciente en América Latina. En especial, expresa el vigor de un conjunto de trabajos que, desde diversas perspectivas disciplinares y abordajes empíricos, siguen discutiendo en la actualidad el tema de la nueva izquierda en los años sesenta y setenta. Es que Hacer la revolución sintetiza tres problemáticas claves de este corpus bibliográfico, las cuales dan lugar a distintas posiciones, debates e interrogantes.

La primera cuestión es la clásica dificultad epistemológica propia de la operación histórica y político-intelectual que implica retrotraerse a un pasado conflictivo y traumático. Para el periodo que nos ocupa, Oscar Terán (1992) propuso la consigna "ni demasiado cerca, ni demasiado lejos”. A su entender, para abordar las décadas del sesenta y setenta es necesario mantener una distancia crítica, pero como lo que está en juego también son pasiones, tragedias y apuestas políticas, es imprescindible involucrarse y discutir. Esta forma de acercamiento es lo que logra Marchesi al indagar en una

\footnotetext{
${ }^{1}$ Becario del Programa de Becas Postdoctorales de la Universidad Nacional Autónoma de México, en el Instituto de Investigaciones Sociales, bajo la asesoría del Dr. Sergio Zermeño y García-Granados.
} 


\section{Dip, N. / Aldo Marchesi, Hacer la revolución. Guerrillas latinoamericanas, de los años sesenta a la caída del muro}

generación de cono sureños, mayoritariamente proveniente de sectores medios y compuesta por jóvenes menores de 30 años, que optó por la lucha armada. Su experiencia cuestionaba las maneras tradicionales de hacer política, pero a la vez se vio atravesada por la emergencia de regímenes dictatoriales de nuevo tipo, que instaurarían en sus versiones más represivas la desaparición sistemática de personas. La escalada de golpes de Estado es conocida: Brasil en 1964; Bolivia en 1966; Argentina en 1966; Bolivia nuevamente en 1971; Uruguay con su "vía democrática al autoritarismo" en 19721973; Chile en 1973 y Argentina nuevamente en 1976.

En este marco, el libro se pregunta directamente ¿cómo evaluar la revolución desde un tiempo que no es revolucionario? Para responder, Marchesi retoma la idea de Françoise Dosse (2012) sobre la legitimidad de un anacronismo controlado. Esta operación le permite realizar dos movimientos centrales. El primero lo aleja de un anacronismo a secas, cuestionando tanto a los enfoques académicos y testimoniales que exaltan acríticamente a dicha generación, como a las visiones condenatorias, herederas de los trabajos de los años 80', que en el contexto del retorno a la democracia enfatizaban anacrónicamente la cultura antiliberal de sus prácticas. Mientras el segundo movimiento lo lleva a reconocer que estamos estudiando desde otra época, pero eso no quita la necesidad de valorar esas experiencias pasadas y resaltar que ciertos aspectos de la contingencia histórica requieren ser entendidos en sus propios términos. Por esta razón, elige mostrar la complejidad y las tensiones que generó la participación de parte de esta generación en una red de organizaciones armadas sudamericana, la cual actuó más de una década y se cristalizó en la aparición de la Junta de Coordinación Revolucionaria (JCR), una articulación entre el Movimiento de Liberación Nacional Tupamaros (MLNT) de Uruguay, el Movimiento de Izquierda Revolucionaria (MIR) de Chile, el Ejército de Liberación Nacional (ELN) Boliviano y el Ejército Revolucionario del Pueblo (ERP) de Argentina.

La segunda problemática que expresa Hacer la revolución está relacionada a la definición de las escalas y los casos de análisis. En este punto, la perspectiva de Marchesi se diferencia de los trabajos hiperespecializados que conciben a los fenómenos nacionales y a los actores de forma estanca. De esta manera, muchas veces parece que cada país tiene una experiencia desconectada del resto y que los protagonistas de las historias 
estudiadas actúan en mundos paralelos entre sí, y no dentro de una red donde se articulan conflictivamente distintas grupalidades y orientaciones. Frente a este panorama, el libro parte de un cruce bibliográfico entre autores latinoamericanos y de habla inglesa para proponer un enfoque trasnacional centrado en las circulaciones de ideas, debates y actores. Esta concepción le permite a Marchesi reconstruir cómo se fue gestando la red de organizaciones armadas del cono sur, la cual fue capaz de impulsar una cultura política regional que, si bien reconocía el liderazgo de la Revolución Cubana y su idea de cambio continental, se alejaba de su estrategia clásica de foco rural y ponía en primer plano la guerrilla urbana, a partir de las características específicas de los países donde operaban.

Lo interesante es que esta posición no es analizada como una concepción ideológica tomada de antemano, sino como una trayectoria que se fue construyendo con idas y vueltas al calor de los intercambios y las amenazas que experimentaban los militantes armados, sobre todo a fines de los sesenta y principios de los setenta; aunque el trabajo incluso deja reflexiones sobre sus itinerarios en décadas posteriores a las transiciones democráticas sudamericanas. En todo este lapso temporal, es ponderada como una dimensión central sus debates compartidos en el exilio, debido a que el ascenso y la escalada de regímenes autoritarios activaron la circulación de ideas y personas, primero en Uruguay, luego en Chile y por último en Argentina. E incluso, Marchesi llega a afirmar que hasta el golpe de Estado de 1976 en éste país, los exilios funcionaban como justificación de espacios de retaguardia para reimpulsar la revolución, a la vez que la propia dinámica trasnacional de las dictaduras inducía a las agrupaciones armadas a una coordinación regional a través de la JCR.

Lo que el libro deja abierto para futuros análisis es la idea de circulaciones inversas y la necesidad de repensar la geografía de protesta de los años sesenta en su conjunto. Como las revoluciones del siglo XIX, por lo general 1968 es conceptualizado como un año paradigmático a partir de la centralidad de Europa Occidental y los Estados Unidos. Pero para Marchesi no sólo es imperioso reconstruir el lugar del cono sur en los sesenta globales y sus propios 1968, sino pensar el papel y la influencia de las periferias en las ideas y repertorios de protesta de los países centrales. En este punto, esboza algunas pistas, como el impacto global de la muerte del Che en Bolivia, las acciones novedosas de guerrilla urbana de los tupamaros y los debates sobre la transición al socialismo en Chile, durante el gobierno de Salvador Allende. 


\section{Dip, N. / Aldo Marchesi, Hacer la revolución. Guerrillas latinoamericanas, de los años sesenta a la caída del muro}

La tercera problemática con que puede ponerse en debate el trabajo está relacionada a las tensiones entre política y cultura, en el marco de la nueva izquierda de esos años. Según Omar Acha (2012) existen investigaciones que hacen una violentología de la historia reciente, ya que reducen las experiencias contestatarias a la violencia y la lucha armada. Aunque a su vez hay un conjunto de autores más sofisticados que sostienen, como el mexicano Sergio Zermeño (1978), el chileno Manuel Antonio Garretón (1985) y la argentina Beatriz Sarlo (2001), que la politización y radicalización de ese período a lo único que llevaron fue a una disolución de las cuestiones culturales e intelectuales. Con la primacía de la política, el tema de la cultura quedó desdibujado. Frente a esto último, el libro muestra cómo una extensa bibliografía sobre los sesenta globales también se hace eco de esta tensión, entre posiciones que enfatizan el carácter laxo de una contracultura trasnacional y otras que insisten en las dimensiones políticas y revolucionarias.

Dentro de este campo de estudio, Marchesi opta por una visión amplia de la nueva izquierda, tributaria de los historiadores norteamericanos Van Gosse (1993) y Eric Zolov (2008), como de las investigadoras rioplatenses, Cristina Tortti (2009) y Vania Markarian (2012). De esta manera, Hacer la revolución trata sobre el trayecto de las organizaciones armadas que confluyeron en la JCR, pero las ubica en un "movimiento de movimientos", donde se pusieron en juego distintas experiencias sociales, políticas y culturales. Así, el libro indaga en conjunto prácticas armadas y no amadas, cruces en entre la vieja y la nueva izquierda, como distintos puentes entre contracultura y política revolucionaria. En este plano, el estudio evidencia fuertes potencialidades y en vez de hablar de primacía de la política o de la cultura, muestra cómo ambas esferas se articulaban de manera compleja con la reflexión sobre la violencia insurgente.

Este tratamiento de la temática se evidencia en el abordaje de dos cuestiones centrales. La primera es el reconocimiento del fuerte trabajo intelectual que implicó la legitimación y el debate sobre la lucha armada, ya sea a través de una red de publicaciones regionales (que incluía desde Punto Final en Chile, Época y Marcha en Uruguay, hasta Pasado y Presente y Cristianismo y Revolución en Argentina) o de apuestas más complejas vinculadas al desarrollo de las ciencias sociales en la región, como el Centro de Estudios Socio Económicos (CESO) de la Universidad de Chile y el 
Centro de Estudios de la Realidad Nacional (CEREN) de la Universidad Católica, dos usinas intelectuales que siguieron el derrotero del gobierno de Salvador Allende y la Unidad Popular.

Mientras la segunda hace referencia al no menos importante papel que cumplieron prácticas culturales como la poesía, la que Marchesi aborda más allá de que los historiadores no estamos acostumbrados a trabajarla como fuente histórica, dado que la literalidad con que tendemos a usar las fuentes es opuesta a la polisemia del lenguaje poético. En este punto, el trabajo muestra cómo junto con la lectura política de la muerte de Ernesto Guevara en 1967, también existió una lectura sentimental de su deceso que influyó en la trayectoria de los militantes del período. Esta última se expresa en los poemas que publicaron revistas de la izquierda sudamericana en los meses de octubre y noviembre. Escritos como "Che" del argentino Julio Huasi ("amor o muerte, Che, vengaremos tu amor"), editado primero en Punto Final y luego en Cristianismo y Revolución, llevan a Marchesi a afirmar que la poesía potenció una subjetividad que enfatizaba el valor ético del sacrificio y la violencia, en oposición al confort ofrecido por la sociedad de consumo. Así, el estudio desmenuza la circulación de dos lenguas juveniles que en su intersección marcaron los matices de la época: el lenguaje del amor vinculado a la contracultura estadounidense y la prédica de las armas en las apuestas revolucionarias latinoamericanas.

Todo libro puede ser sugerido recurriendo a diversos argumentos. La lectura de Hacer la revolución es valiosa no sólo porque indaga una experiencia escasamente trabajada, como el caso de la JCR, sino porque es capaz de abordar y sumar nuevas perspectivas al campo de la historia reciente, en especial a los estudios sobre la nueva izquierda. Las tres problemáticas descriptas anteriormente con que entra en diálogo y la forma de abordarlas manifiestan sus potencialidades. En síntesis, puede arriesgarse que el trabajo de Marchesi requiere ser leído y debatido por su distancia crítica pero comprometida, por su capacidad de trazar una trama trasnacional de actores y por sus esfuerzos por investigar mayores intersecciones entre política y cultura.

\section{Referencias}

Acha, O. (2012). Un revisionismo histórico de izquierda y otros ensayos de política intelectual. Buenos Aires: Ediciones Herramienta. 
Dip, N. / Aldo Marchesi, Hacer la revolución. Guerrillas latinoamericanas, de los años sesenta a la caída del muro

Dosse, F. (2012). Del uso razonado del anacronismo. En El giro reflexivo de la historia. Recorridos epistemológicos y atención a las singularidades. Santiago: Universidad Finis Terrae.

Garretón, M. A. y Martínez, J. (1985). Biblioteca del movimiento estudiantil. Santiago de Chile: Ediciones Sur.

Gosse, V. (1993). Where the Boys Are: Cuba, Cold War America and the Making of a New Left. Estados Unidos: Verso.

Markarian, V. (2012). El 68 uruguayo. El movimiento estudiantil entre molotovs y música beat. Bernal: Universidad Nacional de Quilmes.

Sarlo, B. (2001). La batalla de las ideas. Buenos Aires: Ariel.

Sigal, S. y Terán, O. (abril de 1992). Los intelectuales frente a la política. Punto de Vista, 42.

Tortti, M. C. (209). El viejo partido socialista y los orígenes de la nueva izquierda. Buenos Aires: Prometeo.

Zermeño, S. (1978). México: una democracia utópica. El movimiento estudiantil del 68. México: Siglo XXI.

Zolov, E. (2008). Expanding our Conceptual Horizons: The Shift from an Old to a New Left in Latin America. A Contracorriente, 5(2), 47-73. 
Nicolás Dip

Secuencia. E-ISSN 2395-8464 http://secuencia.mora.e du.mx/ 